\title{
The Arg282Ser missense mutation in APOA5 gene determines a reduction of triglyceride and LDL-cholesterol in children, together with low serum levels of apolipoprotein A-V
}

\author{
Laura Bertoccini ${ }^{1 \dagger}$, Federica Sentinelli ${ }^{1 \dagger}$, Michela Incani ${ }^{2}$, Diego Bailetti ${ }^{1}$, Flavia Agata Cimini ${ }^{1}$, Ilaria Barchetta ${ }^{1}$, \\ Maria Gisella Cavallo ${ }^{1}$, Efisio Cossu², Andrea Lenzi ${ }^{1}$, Sandro Loche ${ }^{3}$ and Marco Giorgio Baroni ${ }^{1,4^{*}}$
}

\begin{abstract}
Background: Apolipoprotein A-V (ApoA-V) is a recognized regulator of plasma triglycerides (TGs), and previous studies have shown associations between variants in APOA5 (apolipoprotein-A5) gene and high TG levels. Recently, a new association between the Arg282Ser missense mutation (rs778114184 G > T) in APOA5 gene and decreased triglyceride levels has been shown in an adult population from Sardinia.

In this study we add further insight into the role of APOA5 by exploring whether this association begins early in life in children, or becomes manifest only in adulthood. We performed the genetic association analysis of APOA5 in a cohort of 925 overweight and obese children and adolescents from Sardinia, Italy, to see if the genetic burden is already at play before modifying risk factors are interacting.
\end{abstract}

Results: We identified 24 heterozygous subjects for the Arg282Ser variant and no homozygous subject. Here we show that the Arg282Ser mutation in APOA5 gene is associated with a significant reduction of TG ( -15. $5 \mathrm{mg} / \mathrm{dl})$, total $(-18.1 \mathrm{mg} / \mathrm{dl})$ and LDL-cholesterol $(-14.8 \mathrm{mg} / \mathrm{dl})$ levels in overweight/obese children and adolescents, indicating that indeed this association appears early in life. Also, we observed a significant reduction in serum apoA-V levels in heterozygous children.

Conclusions: Our data clearly show that the Arg282Ser mutation in APOA5 gene determines a reduction of TG, total and LDL-cholesterol and apolipoprotein A-V levels in overweight/obese children and adolescents, demonstrating that this mutation has the power to affect lipid levels already since childhood.

Keywords: APOA5 variant, Lipids, Children, Obesity, Apolipoproteins, Triglycerides

\section{Background}

Lipid concentrations are heritable traits. Population and family studies suggest that lipid levels have a genetic component with heritability estimates for triglycerides (TGs), total cholesterol, LDL and HDL-cholesterol varying between 48 to $59 \%$ [1].

\footnotetext{
* Correspondence: marco.baroni@uniroma1.it

${ }^{\dagger}$ Equal contributors

'Department of Experimental Medicine, Sapienza University of Rome,

Policlinico Umberto I, 00161 Rome, Italy

${ }^{4}$ Neuromed, Pozzilli, IS, Italy

Full list of author information is available at the end of the article
}

Recently Sidore et al. [2] described, by whole-genome sequencing in 6602 subjects from Sardinia, Italy, a new association between the missense mutation Arg282Ser (rs778114184) in APOA5 gene and decreased triglyceride (TG) levels.

Moreover, the authors reported that this is the strongest variant modulating triglycerides levels in Sardinia, explaining almost $1 \%$ of the phenotypic variance.

Aside from the Sardinian population, the Arg282Ser variant has been found in only two chromosomes in $>30.000$ 
Europeans characterized in the Exome Aggregation Consortium [2].

The APOA5 gene (apolipoprotein-A5) is located on human chromosome 11 at position 11q23. The gene for apolipoprotein A-V (apoA-V) is small, spanning approximately $3 \mathrm{kbp}$, is composed of 4 exons and 3 introns and codes for the 366 amino acid protein apoA-V. In humans, APOA5 is expressed almost exclusively in the liver tissue [3]; some minor expressions have also been detected in the small intestine [4].

ApoA- $\mathrm{V}$ has been identified as an important determinant of plasma TG levels in humans and mice since its discovery [3, 5]. An inverse correlation between plasma apoA-V and TG levels has been reported from animal studies $[3,6]$, which has led to the idea that plasma apoA-V levels would correlate negatively with plasma TG levels in humans. However, recent studies in human subjects using semi-quantitative immunoassays do not support such a relationship [7], showing instead a positive correlation between apoA-V levels and TG levels. ApoA-V may influence plasma triglyceride levels by different possible mechanisms, including effects on lipoprotein lipase [8], on VLDL secretion [9] and on hepatic uptake of lipoprotein remnants [10]. Despite these possible effects, the mechanism of apoA-V action, particularly in humans, remains unclear.

Several SNPs within the APOA5 gene have been associated with changes in plasma TG levels. Population frequencies of common APOA5 alleles exhibit large interethnic differences. For example, there are about $15 \%$ of carriers of the $-1131 \mathrm{C}$ allele of rs662799 variant among Caucasians, but the frequency could reach even $40 \%$ to $50 \%$ among Asians, although the strongest effect on plasma TG levels has been observed in Hispanics [11].

More than twenty rare variants have been described within the human APOA5 gene [11-14]. They cover a wide spectrum that includes stop codons, amino acid changes, as well as insertions and deletions. These mutations are generally associated with hypertriglyceridemia, but penetration is usually not $100 \%$ [15]. The missense mutation Arg282Ser (rs778114184) in APOA5 gene is seemingly the only one associated with decreased triglyceride levels [2].

Since the association between the Arg282Ser mutation in APOA5 gene and TG levels has been evaluated and observed only in an adult population (mean age of 43.5) [2], we performed a genetic association analysis in a cohort of overweight and obese children and adolescents from Sardinia, Italy. Our aim was to provide further insight into the role of APOA5 gene by exploring whether the association between the Arg282Ser variant and TG levels is present in this young cohort, when modifying factors may have had only a short time to act, in order to establish whether the genetic predisposition towards reduced TG levels begins early in life.

\section{Methods \\ Study subjects}

For this study, a total of 925 overweight/obese children (438 males and 487 females) were recruited from the outpatient clinic of the Pediatric Endocrine Unit for excess body weight, at the Regional Hospital for Microcitaemia in Cagliari, Italy. Presence of endocrine disorders or genetic syndromes was considered as exclusion criteria. None of the subjects were taking any form of medication. Anthropometric, demographic and clinical data were collected at time of enrolment as described before [16]. Body mass index standard deviation score (SDS-BMI) was defined according to Italian growth charts in people aged $2-20$ years. SDS-BMI $>1$ and $>2$ were used to define overweight and obesity, respectively [17]. Pubertal development stages were determined in conformity with Tanner scale and subjects were divided into two groups: pre-pubertal (Tanner's stage I) and pubertal (Tanner's stages II-V).

The University Ethical Committee approved the study (ref n. 45/08/CE), and informed written consent was obtained from the children or their legal guardians.

\section{Laboratory determinations}

Blood glucose, insulin, total cholesterol, LDL- and HDLcholesterol, triglycerides, alanine aminotransferase (ALT) and aspartate aminotransferase (AST) were measured in all overweight and obese children in the fasting state. Systolic and diastolic blood pressure was measured three times after a 10 min rest and the mean value was used in subsequent analyses.

Plasma glucose was determined by the glucose oxidase method (Autoanalyzer, Beckman Coulter, Fullerton, CA). Plasma insulin concentration was measured on frozen samples using a radioimmunoassay (DLS-1600 Insulin Radioimmunoassay Kit, Diagnostic System Laboratories Inc., Webster, TX) with an intra-assay coefficient of variation $(\mathrm{CV})$ between $4.7 \%$ and $12.2 \%$ and an inter-assay CV between $4.5 \%$ and $8.3 \%$.

ApoA-V levels were measured by a non-selective enzyme-linked immunosorbent assay (ELISA) kit (Aviva System Biology, San Diego CA) on sera frozen immediately after separation and stored at $-80{ }^{\circ} \mathrm{C}$. The intra and mean inter-assay precision was $\leq 3.6 \%$ and $\leq 7.9 \%$ respectively as reported by the manufacturer.

\section{Surrogate indices of insulin-resistance and secretion}

HOMA-IR (homeostatic model assessment of insulin resistance) for insulin-resistance assessment, HOMA-B (homeostatic model assessment for beta-cell function) 
for insulin secretion evaluation were calculated as previously shown by Matthews et al. [18].

\section{Genotyping assay}

The rs778114184 G > T variant was detected by PCR amplification and high resolution melting analysis (HRM) on an $\mathrm{Eco}^{\mathrm{Tm}}$ Real-Time PCR System by Illumina. Fragments were amplified in a reaction volume of $10 \mu \mathrm{L}$ with $0.5 \mu \mathrm{M}$ of each primer, $10 \mathrm{ng}$ of genomic DNA, and 1× LCGreen Plus + Melting Dye. After an initial polymerase activation step at $95{ }^{\circ} \mathrm{C}$ for $3 \mathrm{~min}$, amplification was performed using 42 cycles of denaturation $\left(95{ }^{\circ} \mathrm{C}\right.$ for $15 \mathrm{~s}$ ) and annealing $\left(60{ }^{\circ} \mathrm{C}\right.$ for $\left.1 \mathrm{~min}\right)$. After amplification, a final melting curve was recorded by heating to $95^{\circ} \mathrm{C}$ for $15 \mathrm{~s}$, cooling to $65^{\circ} \mathrm{C}$ for $15 \mathrm{~s}$, and holding until $95^{\circ} \mathrm{C}$. Mutation carriers were sequenced for validation.

To ensure long-term reproducibility of the method in each experiment, two control samples carrying GG and GT genotypes were run each time.

\section{Statistical analysis}

All statistical analyses were performed with SPSS 17.0 statistical package. Skewed variables were logarithmically transformed before the analyses. Categorical variable distribution was compared by $\mathrm{X}^{2}$ test. Differences between continuous variables across the genotype classes were evaluated by ANOVA. $P$ values were calculated using a linear regression model including gender, age, BMI-SDS, and Tanner stage.

Power calculation: given a standard deviation in TG levels in our population of $35 \mathrm{mg} / \mathrm{dl}$ [19] the size of the study cohort had the power of $80 \%$ to detect, with an alpha error of 0.05 , a mean difference of $20.7 \mathrm{mg} / \mathrm{dl}$ [2] in triglyceride levels across different genotypes.

\section{Results}

Among the 925 children studied we identified 24 heterozygous subjects for the rs778114184 variant and no homozygous subject. The genotype frequencies were in Hardy-Weinberg-Equilibrium.

We then analysed the association between the polymorphism and clinical and biochemical characteristics (Table 1).

Carriers of the mutation showed significantly reduced levels of TGs (GT vs GG, $48.2 \pm 31.6$ vs $63.7 \pm 39.5$, $p=0.001$ ), total cholesterol (GT vs GG, $149.7 \pm 25.3$ vs $167.8 \pm 32.3, p=0.005$ ), and LDL-cholesterol (GT vs GG, $88.6 \pm 22.6$ vs $103.4 \pm 28.2, p=0.016$ ) (Fig. 1 a, b and c). Thus, the mutation Arg282Ser (rs778114184 $\mathrm{G}>\mathrm{T}$ ) in $A P O A 5$ gene is associated with a reduction of TG $(-15.5 \mathrm{mg} / \mathrm{dl})$, total $(-18.1 \mathrm{mg} / \mathrm{dl})$ and LDLcholesterol $(-14.8 \mathrm{mg} / \mathrm{dl})$ levels in overweight/obese children and adolescents.
Table 1 Clinical characteristics of overweight and obese children and adolescents stratified by ApoA5 genotype

\begin{tabular}{|c|c|c|c|}
\hline & \multicolumn{2}{|l|}{ Genotypes } & \multirow[t]{2}{*}{$P$} \\
\hline & $\begin{array}{l}\mathrm{GG} \\
\text { n. }=901\end{array}$ & $\begin{array}{l}\mathrm{GT} \\
\mathrm{n} .=24\end{array}$ & \\
\hline Females/Males* & $477 / 424$ & $10 / 14$ & 0.380 \\
\hline Age (years) & $10.4 \pm 3.2$ & $9.9 \pm 3.2$ & 0.500 \\
\hline Weight (Kg) & $57 \pm 19.8$ & $55 \pm 18.5$ & 0.602 \\
\hline $\mathrm{BMI}\left(\mathrm{Kg} / \mathrm{m}^{2}\right)$ & $27.4 \pm 4.2$ & $29.1 \pm 9.3$ & 0.216 \\
\hline SDS-WEIGHT & $1.5 \pm 0.9$ & $1.5 \pm 0.8$ & 0.855 \\
\hline SDS-BMI & $2.8 \pm 1.2$ & $3.6 \pm 2.9$ & 0.103 \\
\hline $\mathrm{SBP}(\mathrm{mm} / \mathrm{Hg})$ & $106 \pm 14.8$ & $105 \pm 14.6$ & 0.811 \\
\hline $\mathrm{DBP}(\mathrm{mm} / \mathrm{Hg})$ & $61.7 \pm 8.8$ & $63 \pm 8.7$ & 0.515 \\
\hline $\mathrm{TC}(\mathrm{mg} / \mathrm{dl})$ & $167.8 \pm 32.3$ & $149.7 \pm 25.3$ & 0.005 \\
\hline $\mathrm{TG}(\mathrm{mg} / \mathrm{dl})$ & $63.7 \pm 39.5$ & $48.2 \pm 31.6$ & 0.001 \\
\hline HDL-C (mg/dl) & $51.5 \pm 12.2$ & $51.2 \pm 11.1$ & 0.996 \\
\hline LDL-C (mg/dl) & $103.4 \pm 28.2$ & $88.6 \pm 22.6$ & 0.016 \\
\hline AST (U/L) & $24.4 \pm 10.7$ & $25.6 \pm 5.9$ & 0.591 \\
\hline $\mathrm{ALT}(\mathrm{U} / \mathrm{L})$ & $23 \pm 12.5$ & $22.6 \pm 7.8$ & 0.873 \\
\hline BG $0^{\prime}(\mathrm{mg} / \mathrm{dl})$ & $89 \pm 7.6$ & $88.2 \pm 6.3$ & 0.656 \\
\hline BG 120' (mg/dl) & $105.5 \pm 20.2$ & $113.2 \pm 17$ & 0.055 \\
\hline Ins $0^{\prime}(\mu \mathrm{UI} / \mathrm{ml})$ & $14.7 \pm 9.1$ & $17.9 \pm 12.4$ & 0.376 \\
\hline Ins 120' ( $\mu \mathrm{UI} / \mathrm{ml})$ & $61.4 \pm 51$ & $90.3 \pm 73.5$ & 0.087 \\
\hline HOMA-IR (U) & $3.3 \pm 2.1$ & $4 \pm 2.8$ & 0.421 \\
\hline HOMA-B & $218.3 \pm 183$ & $257.3 \pm 177.6$ & 0.314 \\
\hline
\end{tabular}

Values are expressed as means \pm standard deviations

Abbreviations: $B M I$ body mass index, SDS Standard Deviation Score, SBP systolic blood pressure, DBP diastolic blood pressure, TC total cholesterol, TG plasma triglycerides, $H D L-C$ high density lipoprotein-cholesterol, $L D L-C$ low density lipoprotein cholesterol, AST aspartate aminotransferase, $A L T$, alanine aminotransferase, $B G$ blood glucose, Ins insulin, HOMA-IR homeostatic model assessment of insulin resistance, HOMA-B homeostatic model assessment for beta-cell function $U$, Unit

*P value was calculated by $X 2$. $P$ values $<0.05$ are considered significant

Additionally, multiple linear regression analysis was performed to estimate which variables were independently associated with serum triglycerides (Table 2). We observed that BMI $(p<0.001)$, Arg282Ser mutation $(\mathrm{p}<0.001)$, and HOMA-IR $(\mathrm{p}<0.001)$ were significantly and independently associated with serum triglyceride levels. Also, with the same model, a significant independent association was observed between the APOA5 Arg282Ser mutation and total- (Table 3) and LDLcholesterol (Table 4).

Next, we measured serum apolipoprotein A-V concentration in the 24 carriers of the rs778114184 variant and in a group of wild-type children, matched for sex, age and BMI; our aim was to test if there was a difference in apoA-V levels between carriers and noncarriers of the Arg282Ser mutation in APOA5 gene.

We observed that serum ApoA-V levels were significantly lower in heterozygous than wild type subjects $(3.07 \pm 0.78$ 


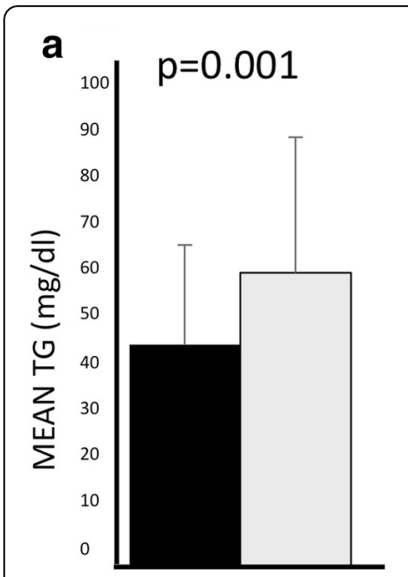

GT

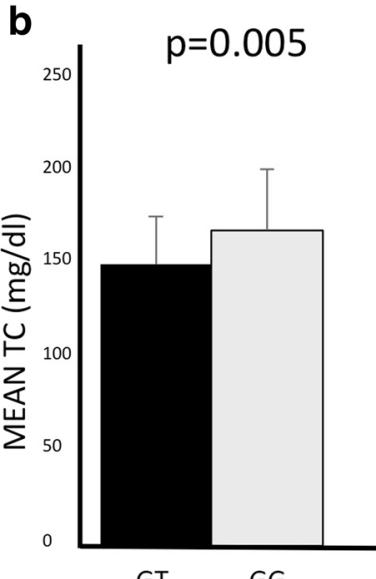

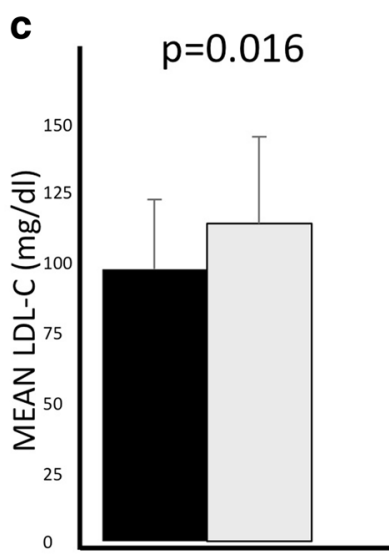

GT

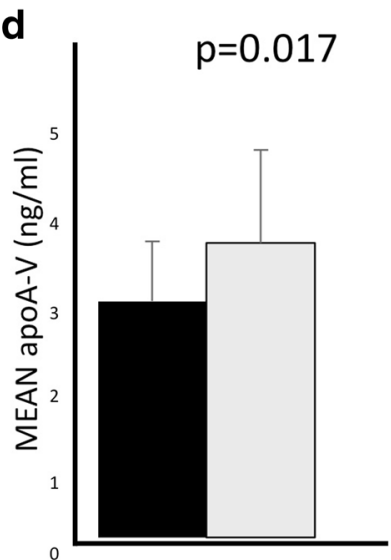

GT

GG

Fig. 1 Association between ApoA5 genotypes and lipid profile in a cohort of overweight and obese children and adolescents. Mean plasma levels of (a) triglycerides (TG), (b) total cholesterol (TC) and (c) LDL- cholesterol (LDL-C) stratified by ApoA5 genotypes. $P$ values were calculated using linear regression including age, gender, BMI and Tanner stage as covariates. Mean serum levels of (d) ApoA5 protein in a subgroup of 24 heterozygous and 20 wild-type children stratified by ApoA5 genotypes

vs $3.83 \pm 1.22 \mathrm{ng} / \mathrm{ml}, p=0.017$ ) (Fig. $1 \mathrm{~d}$ ) demonstrating a direct relation between TG and apoA-V levels.

\section{Discussion}

Apolipoprotein $\mathrm{A}-\mathrm{V}$ is a key regulator of plasma triglycerides. Here we show that the mutation Arg282Ser (rs778114184 $\mathrm{G}>\mathrm{T}$ ) in APOA5 gene is associated with a reduction of TG, total and LDLcholesterol levels in overweight/obese children and adolescents, showing that this association appears early in life and that the genetic burden is already at play before modifying risk factors interact. In agreement with the observation from Sidore et al. [2] we also observed that the Arg282Ser mutation in APOA5 gene explained almost $1 \%$ of the total variance in TGs in our cohort, further underlining the relevant role played by this variant in the genetic determination of the trait.

Table 2 Multiple linear regression analysis

\begin{tabular}{llll}
\hline $\begin{array}{l}\text { Independent } \\
\text { Variable }\end{array}$ & $\begin{array}{l}\text { Standardized } \\
\text { Regression } \\
\text { Coefficients }\end{array}$ & $\begin{array}{l}\mathrm{t} \\
\text { value }\end{array}$ & $P$ \\
\hline Age & 0.029 & 0.628 & 0.530 \\
BMI & 0.153 & 3.761 & $<0.001$ \\
Gender & 0.015 & 0.458 & 0.647 \\
TANNER'S STAGE & -0.017 & -0.379 & 0.705 \\
Arg282Ser SNP & -0.134 & -4.229 & $<0.001$ \\
HOMA-IR & 0.192 & 5.513 & $<0.001$
\end{tabular}

Triglycerides are the dependent variable

Abbreviations: BMI body mass index, HOMA-IR homeostatic model assessment of insulin resistance

$P$ values $<0.05$ are considered significant
These results were confirmed by multivariate regression analysis, where a negative independent association was observed for the Arg282Ser variant in APOA5 gene. In addition, we observed a significant reduction in serum apoA-V levels in heterozygous children, highlighting a direct relation between low apoA-V concentration and low TGs.

Interestingly, the concept that apoA-V and TGs are directly related is supported by several epidemiological studies [7, 20-23]. Indeed, the notion that apoA-V and triglycerides are positively related is supported by findings by Dallinga-Thie et al. [20] in patients with type 2 diabetes, by Vaessen et al. [21] in more than 3000 individuals and by Henneman et al. [22] in patients with severe hypertriglyceridemia. In addition, the direct relationship between apoA-V and TG levels observed in the current analysis further agrees with previous studies by Schaap et al. [7]

Table 3 Multiple linear regression analysis

\begin{tabular}{llll}
\hline $\begin{array}{l}\text { Independent } \\
\text { Variable }\end{array}$ & $\begin{array}{l}\text { Standardized } \\
\text { Regression } \\
\text { Coefficients }\end{array}$ & $\begin{array}{c}\mathrm{t} \\
\text { value }\end{array}$ & $P$ \\
\hline Age & 0.015 & 0.311 & 0.756 \\
BMI & -0.022 & -0.522 & 0.602 \\
Gender & 0.045 & 1.337 & 0.182 \\
TANNER'S STAGE & -0.125 & -2.754 & 0.006 \\
Arg282Ser SNP & -0.091 & -2.743 & 0.006 \\
HOMA-IR & 0.058 & 1.597 & 0.111 \\
\hline
\end{tabular}

Total cholesterol is the dependent variable

Abbreviations: BMI body mass index, HOMA-IR homeostatic model assessment of insulin resistance

$P$ values $<0.05$ are considered significant 
Table 4 Multiple linear regression analysis

\begin{tabular}{llll}
\hline $\begin{array}{l}\text { Independent } \\
\text { Variable }\end{array}$ & $\begin{array}{l}\text { Standardized } \\
\text { Regression } \\
\text { Coefficients }\end{array}$ & $\begin{array}{c}\mathrm{t} \\
\text { value }\end{array}$ & $P$ \\
\hline Age & 0.007 & 0.133 & 0.894 \\
BMI & -0.44 & -1.039 & 0.299 \\
Gender & 0.025 & 0.738 & 0.460 \\
TANNER'S STAGE & -0.090 & -1.966 & 0.050 \\
Arg282Ser SNP & -0.076 & -2.294 & 0.022 \\
HOMA-IR & 0.102 & 2.809 & 0.005 \\
\hline
\end{tabular}

LDL- cholesterol is the dependent variable

Abbreviations: BMI body mass index, HOMA-IR homeostatic model assessment of insulin resistance

$P$ values $<0.05$ are considered significant

in patients with markedly elevated TGs and by Talmud et al. [23] in patients with type 2 diabetes.

These observations are in contrast with experiments in animal models, where an inverse correlation between apoA-V concentrations and plasma TG concentrations was detected [7]. The reason for the positive correlation between apoA-V and TGs in humans and the negative correlation in mouse models is unclear, but it suggests that, for apoA- $\mathrm{V}$, inferring from animal models to man should be made with caution [23].

The study performed by Schaap et al. [7] for example provides evidence for a complex interaction between apoA-V and apoC-III. The relative amounts of apoA-V and apoC-III in plasma, and most likely their distribution over lipoproteins, may influence LPL activity and ultimately TG levels [7]. It is evident the need for additional studies to clarify the role of apoA-V in human TGs metabolism.

With regards to the association between $A P O A 5$ and total and LDL-cholesterol, our observation is in line with a previous report showing the same association in GWAs [24]. Which mechanism is involved is a matter of speculation, since to the best of our knowledge, there are no studies exploring this relationship. We could speculate that, by reducing VLDL levels, all the following steps (IDL, remnants) leading to LDL formation from VLDL might be affected.

Strengths of our study rely on the collection of a very well clinically characterized cohort of children from Sardinia, where the Arg282Ser mutation is more common [2] compared to other populations. Moreover, genetic studies performed in children allow reducing the effect of confounding factors, such as diet, physical activity and lifestyle, on the trait under study.

The main limitation of this study is its crosssectional design, which does not allow establishing a causal link; longitudinal studies are warranted to clarify this question.

\section{Conclusion}

In conclusion, our data clearly show that the Arg282Ser mutation (rs778114184 $\mathrm{G}>\mathrm{T}$ ) in APOA5 gene is associated with a reduction of TG, total and LDL-cholesterol levels in overweight/obese children and adolescents, demonstrating that this mutation has the power to affect lipid levels already since childhood, when other key modifying factors (i.e. lifestyle, diet, physical activity) may have not yet influenced the traits. In addition, we observed a significant reduction in serum apoA-V levels in heterozygous children with lower TG levels, highlighting the direct relation between apoA-V concentration and TGs, as previously shown in large population studies. Given these effects, apoA-V may possibly represent a putative target for drug development.

\section{Abbreviations}

ALT: Alanine aminotransferase; APOA5: Apolipoprotein-A5; APOA-V: Apolipoprotein A-V; AST: Aspartate aminotransferase; BG: Blood glucose; BMI: Body mass index; DBP: Diastolic blood pressure; HDL-C: High density lipoprotein-cholesterol; HOMA-B: Homeostatic model assessment for beta-cell function;

HOMA-IR: Homeostatic model assessment of insulin resistance; HRM: High resolution melting analysis; INS: Insulin; LDL-C: Low density lipoprotein cholesterol; SBP: Systolic blood pressure; SDS: Standard Deviation Score; SDS-BMI: Body mass index standard deviation score; TC: Total cholesterol; TGs: Triglycerides

\section{Funding}

This work was funded by research grants from the Regione Autonoma della Sardegna (Grant RAS 2012 n. CRP-59453), and from the Foundation Banca d'Italia (projects 2015), all awarded to Marco G. Baroni, and from the Sapienza University of Rome "Avvio alla Ricerca" grant to LB.

\section{Availability of data and materials}

The datasets used and/or analysed during the current study are available from the corresponding author on reasonable request.

\section{Authors' contributions}

$L B, F S$ and MGB developed the research question and designed this study. EC, SL and MI were responsible for data collection and database organization, in collaboration with FAC, DB and IB. Experimental analyses were performed by LB, FS and FAC (ApoA-V assays). All authors had full access to all the data (including statistical reports and tables) and made substantial contributions to the analysis and interpretation of data. The paper was written by $L B, F S, D B, M G C, A L$ and $M G B$, and the other authors revised it critically for important intellectual content. All authors have approved the final version of the manuscript.

\section{Ethics approval and consent to participate}

The University of Cagliari Ethical Committee approved the study (ref n. 45/ 08/CE), and informed written consent was obtained from the children or their legal guardians.

\section{Consent for publication}

Not applicable.

\section{Competing interests}

The authors declare that they have no competing interests.

\section{Publisher's Note}

Springer Nature remains neutral with regard to jurisdictional claims in published maps and institutional affiliations.

\section{Author details}

${ }^{1}$ Department of Experimental Medicine, Sapienza University of Rome, Policlinico Umberto I, 00161 Rome, Italy. ${ }^{2}$ Endocrinology and Diabetes, Department of Medical Sciences, University of Cagliari, Cagliari, Italy. 
${ }^{3}$ Pediatric Endocrine Unit, Regional Hospital for Microcitemia, Cagliari, Italy. ${ }^{4}$ Neuromed, Pozzilli, IS, Italy.

Received: 4 June 2017 Accepted: 13 September 2017 Published online: 19 September 2017

\section{References}

1. Kathiresan S, Manning AK, Demissie S, RB D'A, Surti A, Guiducci C, Gianniny L, Burtt NP, Melander O, Orho-Melander M, et al. A genome-wide association study for blood lipid phenotypes in the Framingham heart study. BMC Med Genet. 2007:8(Suppl 1):S17.

2. Sidore C, Busonero F, Maschio A, Porcu E, Naitza S, Zoledziewska M, Mulas A, Pistis G, Steri M, Danjou F, et al. Genome sequencing elucidates Sardinian genetic architecture and augments association analyses for lipid and blood inflammatory markers. Nat Genet. 2015:47:1272-81.

3. Pennacchio LA, Olivier M, Hubacek JA, Cohen JC, Cox DR, Fruchart JC, Krauss RM, Rubin EM. An apolipoprotein influencing triglycerides in humans and mice revealed by comparative sequencing. Science. 2001;294:169-73.

4. Guardiola M, Alvaro A, Vallvé JC, Rosales R, Solà R, Girona J, Serra N, Duran P, Esteve E, Masana L, Ribalta J. APOA5 gene expression in the human intestinal tissue and its response to in vitro exposure to fatty acid and fibrate. Nutr Metab Cardiovasc Dis. 2012;22:756-62.

5. Van der Vliet HN, Sammels MG, Leegwater AC, Levels JH, Reitsma PH, Boers W, Chamuleau RA. Apolipoprotein A-V: a novel apolipoprotein associated with an early phase of liver regeneration. J Biol Chem. 2001;27:644512-20.

6. Van der Vliet HN, Schaap FG, Levels JH, Ottenhoff R, Looije N, Wesseling JG, Groen AK, Chamuleau RA. Adenoviral overexpression of apolipoprotein A-V reduces serum levels of triglycerides and cholesterol in mice. Biochem Biophys Res Commun. 2002;295:1156-9.

7. Schaap FG, Nierman MC, Berbée JF, Hattori H, Talmud PJ, Vaessen SF, Rensen PC, Chamuleau RA, Kuivenhoven JA, Groen AK. Evidence for a complex relationship between apoA-V and apoC-III in patients with severe hypertriglyceridemia. J Lipid Res. 2006;47:2333-9.

8. Li Y, He PP, Zhang DW, Zheng XL, Cayabyab FS, Yin WD, Tang CK. Lipoprotein lipase: from gene to atherosclerosis. Atherosclerosis. 2014;237:597-608.

9. Beckstead JA, Oda MN, Martin DD, Forte TM, Bielicki JK, Berger T, Luty R, Kay CM, Ryan RO. Structure-function studies of human apolipoprotein A-V: a regulator of plasma lipid homeostasis. Biochemistry. 2003;42:9416-23.

10. Nilsson SK, Heeren J, Olivecrona G, Merkel M. Apolipoprotein A-V; a potent triglyceride reducer. Atherosclerosis. 2011;219:15-21.

11. Pennacchio LA, Olivier M, Hubacek JA, Krauss RM, Rubin EM, Cohen JC. Two independent apolipoprotein A5 haplotypes influence human plasma triglyceride levels. Hum Mol Genet. 2002;11:3031-8.

12. Hodoglugil U, Tanyolac S, Williamson DW, Huang Y, Mahley RW. Apolipoprotein A-V: a potential modulator of plasma triglyceride levels in Turks. J Lipid Res. 2006;47:144-53.

13. Kao JT, Wen HC, Chien KL, Hsu HC, Lin SW. A novel genetic variant in the apolipoprotein $\mathrm{A} 5$ gene is associated with hypertriglyceridemia. Hum Mol Genet. 2003:19:2533-9.

14. Hubacek JA, Skodová Z, Adámková V, Lánská V, Pitha J. APOA5 variant Ser19Trp influences a decrease of the total cholesterol in a male 8 year cohort. Clin Biochem. 2006;39:133-6.

15. Melegh BI, Duga B, Sümegi K, Kisfali P, Maász A, Komlósi K, Hadzsiev K, Komoly S, Kosztolányi G, Melegh B. Mutations of the apolipoprotein A5 gene with inherited hypertriglyceridaemia: review of the current literature. Curr Med Chem. 2012;19:6163-70.

16. Cambuli VM, Incani M, Pilia S, Congiu T, Cavallo MG, Cossu E, Sentinelli F, Mariotti S, Loche S, Baroni MB. Oral glucose tolerance test in Italian overweight/obese children and adolescents results in a very high prevalence of impaired fasting glycaemia, but not of diabetes. Diab Metab Res Rev. 2009;25:528-34.

17. Cacciari E, Milani S, Balsamo A, Spada E, Bona G, Cavallo L, Cerutti F, Gargantini L, Greggio N, Tonini G, Cicognani A. Italian cross-sectional growth charts for height, weight and BMI (2 to 20 yr). J Endocrinol Investig. 2006;29:581-93.

18. Matthews DR, Hosker JP, Rudenski AS, Naylor BA, Treacher DF, Turner RC Homeostasis model assessment: insulin resistance and beta-cell function from fasting plasma glucose and insulin concentrations in man Diabetologia. 1985;28:412-9.
19. Sentinelli F, Bertoccini L, Barchetta I, Capoccia D, Incani M, Pani MG, Loche S, Angelico F, Arca M, Morini S, Manconi E, Lenzi A, Cossu E, Leonetti F, Baroni MG, Cavallo MG. The vitamin D receptor (VDR) gene rs 11568820 variant is associated with type 2 diabetes and impaired insulin secretion in Italian adult subjects, and associates with increased cardio-metabolic risk in children. Nutr Metab Cardiovasc Dis. 2016;26:407-13.

20. Dallinga-Thie GM, Van Tol A, Hattori H, Van Vark-van der Zee LC, Jansen $H$, Sijbrands EJ, DALI study group. Plasma apolipoprotein A5 and triglycerides in type 2 diabetes. Diabetologia. 2006;49:1505-11.

21. Vaessen SF, Schaap FG, Kuivenhoven JA, Groen AK, Hutten BA, Boekholdt SM, Hattori H, Sandhu MS, Bingham SA, Luben R, Palmen JA, Wareham NJ, Humphries SE, Kastelein JJ, Talmud PJ, Khaw KT. Apolipoprotein A-V, triglycerides and risk of coronary artery disease: the prospective epic-Norfolk population study. J Lipid Res. 2006;47:2064-70.

22. Henneman P, Schaap FG, Havekes LM, Rensen PC, Frants R, Van Tol A, Hattori H, Smelt AH, Van Dijk KW. Plasma apoAV levels are markedly elevated in severe hypertriglyceridemia and positively correlated with the APOA5 S19W polymorphism. Atherosclerosis. 2007;193:129-34.

23. Talmud PJ, Cooper JA, Hattori H, Miller IP, Miller GJ, Humphries SE. The apolipoprotein $A-V$ genotype and plasma apolipoprotein $A-V$ and triglyceride levels: prospective risk of type 2 diabetes. Results from the Northwick Park heart study II. Diabetologia. 2006;49:2337-40.

24. Johansen $C T$, Kathiresan $S$, Hegele RA. Genetic determinants of plasma triglycerides. J Lipid Res. 2011;52:189-206.

\section{Submit your next manuscript to BioMed Central and we will help you at every step:}

- We accept pre-submission inquiries

- Our selector tool helps you to find the most relevant journal

- We provide round the clock customer support

- Convenient online submission

- Thorough peer review

- Inclusion in PubMed and all major indexing services

- Maximum visibility for your research

Submit your manuscript at www.biomedcentral.com/submit
) Biomed Central 